\title{
Effect of Foaming Agent on the Properties of Superporous Hydrogels Prepared via Solution Polymerization Method
}

\author{
Suriati Ghazali* and Najahusna Adnan \\ Faculty of Chemical and Natural Resources Engineering, University Malaysia Pahang, Gambang - 26300, \\ Pahang, Malaysia; suriati@ump.edu.my
}

\begin{abstract}
Background/Objectives: Superporous hydrogels (SPHs) are three dimensional network polymers that often crosslinked through chemical or physical interactions. It can swell to an equilibrium state and retain a significant amount of water molecule due to the presences of interconnected microscopic pores. The swelling rate of most of the dried hydrogel (i.e. xerogels) typically low and take a longer time to reach equilibrium due to slow water absorption capability. This disadvantage further limits the possible application of the hydrogel to be utilized in various field, includes as drug delivery material and as soil conditioner in agriculture field. Therefore, there is a significant interest in developing synthesis method and the selection of material in preparation of the superporous hydrogel that can exhibit both fast swelling absorption properties. Methods/Statistical Analysis: In this study, SPHs were prepared from monomer of acrylamide (AM) by a solution polymerization reaction process with the assistance of ammonium persulphate (APS) as an initiator and $\mathrm{N}^{\prime} \mathrm{N}^{\prime}$-methylenebisacrylamide (MBA) as cross linker. The effect of sodium bicarbonate $\left(\mathrm{NaHCO}_{3}\right)$ amount as foaming agent to generate pore structure was investigated in term of morphology, water absorbency, and swelling properties of SPHs. Findings: Based on the results, the water absorbency of SPHs increased $65 \%$ by comparing with control sample (0wt\%). Based on the comparison, the increasing foaming agent from $0-0.4 \mathrm{wt} \%$ of sodium bicarbonate shows that water absorbency reached the optimum condition at $0.4 \mathrm{wt} \%$ which is $99.10 \pm 3.35 \mathrm{~g} / \mathrm{g}$. Then, the interaction between hydrogels shows the best fit at $0.4 \mathrm{wt} \%$ with $\mathrm{K}$ value of $1.1905 \mathrm{E}-$ 05. Application/Improvements: SPHs was produced in order to be used in other applications such as agriculture, electrical and separation technology according to its porosity improvement.
\end{abstract}

Keywords: Foaming Agent, Superporous Hydrogels (SPHs), Sodium Bicarbonate, Swelling Properties

\section{Introduction}

Recently, absorbent polymer used in many type of applications such as hygiene, agriculture, horticulture, rubber, fibre, electrical and construction industries. Superabsorbent polymer (SAPs) is a three dimensional (3D) hydrophilic polymer networks that able to imbibe large amount of water ${ }^{1}$. In order to apply in many applications, high swelling rate becomes a major consideration for hydrogel. Present SAPs has slow swelling cause by the slow diffusion of water into the center of matrix of dried hydrogel. Besides, it contains less porous structure, which initiate to the slow swelling properties of the absor- bent polymer. It usually required several hours to reach maximum absorption capacity. In 1998, superpororus hydrogels (SPHs) was introduced by Chen as new type of water-absorbent polymer systems ${ }^{2}$. Superporous hydrogels (SPHs) are a type of absorbent material that can swell up to thousand times of their own weight. According to ${ }^{\underline{3}}$ SPHs comprise interconnected microscopic structure that lead to more porous structure in hydrogels ${ }^{3}$. In addition, SPHs possess more surface area and shorter diffusion distance compared with the conventional hydrogels. As a result, it can swell very fast to a very large size when contact with water. In fact, SPHs can be produced by several methods, including phase separation, foaming technique,

${ }^{*}$ Author for correspondence 
emulsion-template synthesis and particulate leaching and freeze drying 4 . Acrylamide (AM) is one of the monomer that usually consumed in preparation of hydrogel, which is a hydrophilic polymer and have capability of water absorption. Based on this research, superporous hydrogels (SPHs) was synthesized by using solution polymerization method in the presence of foaming agent that will produce gas bubbles from the reaction of foaming agent with cross linker and initiator. Foaming agent will influenced the number of porous structure. According to ${ }^{5}$, there are two type of foaming agent which is neutralization and redox $^{5}$. Neutralization agent includes carbonates and sulphates that decompose when heat, also emitting $\mathrm{CO}_{2}$. The neutralization agent enables to absorb high amount of water approximately $50 \%$ to $70 \%$. The foaming agent that commonly used was originally from inorganic compound, for example sodium bicarbonate $\left(\mathrm{NaHCO}_{3}\right)$. Based on $^{6}, \mathrm{NaHCO}_{3}$ relatively decompose at low temperature in between $145^{\circ} \mathrm{C}$ to $150^{\circ} \mathrm{C}$ and it results open structure cell which increase the ability of hydrogels to swell higher ${ }^{6}$. In contrast, redox agents produced through oxidation reaction with gases such as oxygen and sulphur anhydride. The examples of redox agents such as carbon containing materials like graphite, carbon and coke. Then, the reason $\mathrm{NaHCO}_{3}$ was chosen is because it can form $\mathrm{CO}_{2}$ at low acidic and cell environmental friendly. Besides, former research just studied the general usage as foaming agent in term of foam formation. However, for this research, we was studied the performance of foaming agents towards the water absorbency of superporous hydrogels based on its concentration. In addition, this research also studied the swelling kinetics of hydrogels based on the foaming agent concentration. Lastly, there were slightly difference of this research compared to other research it term of practical used of foaming agent; sodium bicarbonate which determine the swelling kinetics of hydrogels.

\section{Materials and Methods}

Monomers acrylamide (AM), cross linker N'N'methylenebisacrylamide (MBA) were purchased from Fisher Scientific, Malaysia. Initiator ammonium persulphate (APS) and foaming agent sodium bicarbonate $\left(\mathrm{NaHCO}_{3}\right)$ were supplied by Permula Chemical, Malaysia. Then, purified nitrogen gas was provided by Azam Synergy, Pahang, Malaysia. Sodium hydroxide was provided by FKKSA, UMP. All ingredients were used analytical grade.

\subsection{Synthesis Superporous Hydrogels (SPHs)}

Superporous hydrogels were synthesized by the following procedure. $7.1 \mathrm{~g}$ AM ingredients was added sequentially into a $250 \mathrm{ml}$ three neck flask at room temperature $\left(25^{\circ} \mathrm{C}\right)$ in $20 \mathrm{ml}$ distilled water. The $\mathrm{pH}$ of solution was adjusted to 5-5.5 using $20 \mathrm{ml} \mathrm{NaOH}$. The mixture was stirred until dissolve. After that, MBA was added to the mixture solution under nitrogen atmosphere and $0.25 \mathrm{~g} \mathrm{NaHCO}_{3}$ was added $30 \mathrm{~s}$ after the addition of the MBA. Then, water bath was heated to $40^{\circ} \mathrm{C}$ under vigorously stirred at 500 $\mathrm{rpm}$. At $40^{\circ} \mathrm{C}, 0.1 \mathrm{~g}$ APS was added. The polymerization process was allowed to continue for one hour to ensure that full consumption of monomer. After synthesis of SPHs, it was removed with forceps and was cut into pieces about 1-2 cm. Last step, the sample was dried in an oven at $60^{\circ} \mathrm{C}$ until obtain constant weight. The dried SPHs were meshed by using 20-40 meshes sieve for uniform solid sample. SPHs were stored in air tight container to prevent any reaction. The samples were repeated at different amount of foaming additives by using design of experiment (DOE) method.

\subsection{Water Absorbency}

Measurement of water absorbency was performed by a tea bag method. The weight of the dry sample was marked as $M_{1}$ and weight of swollen sample as $M_{2}$. A tea bag which contain dry sample was immersed in the $200 \mathrm{ml}$ distilled water at room temperature for 24 hours. Then, the swollen samples were filtered and hang up until no water drop. The ratio of the swelling was calculated using equation below:

$$
\text { Water Absorbency }=\frac{M_{2}-M_{1}}{M_{1}}
$$

\subsection{Characterization}

\section{Scanning Electron Microscope (SEM)}

Broken part of SPHs was coated with a thin layer of platinum using Hummer sputter coater. Morphology of porous structure was examined using a Jeol JSM-840 scanning electron microscope (SEM), with an operating voltage of $30 \mathrm{kV}$

\section{Fourier Transform Infrared (FTIR) spectroscopy}

The chemical structure of the synthesized hydrogels was investigated by using Fourier Transform Infrared spectroscopy. The FTIR spectrum was recorded over the range of $400-4000 \mathrm{~cm}^{-1}$ by $\mathrm{KBr}$ pellet method using Nicolet, NEXUS TM. 


\section{Swelling Kinetics}

Superporous hydrogels sample were added into tea bags and were immersed in $250 \mathrm{ml}$ of distilled water. At consecutive time intervals, the equilibrium swelling capacity of hydrogels was measured according to the basic formula. Swelling kinetics of superporous hydrogels will be based on Aydınoğlu ${ }^{5}$ reviewed:

$$
\frac{d W}{d t}=k\left(W_{\infty}-W\right)
$$

where $\mathrm{W}_{\infty}$ is the weight of hydrogel at equilibrium, $\mathrm{W}$ is the weight of hydrogels at consecutive time and $\mathrm{K}$ is a constant. The swelling kinetics were analysed in order to find whether swelling of hydrogels follows first order or second orders kinetics. For the first order kinetics, plot straight line graph between the $\ln (\mathrm{W} \infty / \mathrm{W} \infty-\mathrm{W})$ as a function of time. If the graph diverged, consider the second order kinetics expressed as:

$$
\frac{t}{W}=\frac{1}{K W_{\infty}^{2}}+\frac{1}{W_{\infty}} t
$$

Then, if it was found straight line for Equation (3), hence the swelling of hydrogels obeys the second order kinetics.

\section{Results and Discussion}

\subsection{Water Absorbency of Hydrogel at Various Amount of Foaming Agent}

In general, swelling ratio of superporous hydrogels continuously increase until optimum concentration of foaming agent $\left(\mathrm{NaHCO}_{3}\right)$. In fact, using of $\mathrm{NaHCO}_{3}$ towards the hydrogel increase pores in hydrogel structure and give high water uptake. Other than that, increase swelling properties may originate from the greater availability of monomer molecules between polymer chains. Presence of acrylamide monomer enhances the hydrophilicity of hydrogels, thus cause the stronger affinity for more absorption of water. Besides, in reaction equation it shows that acrylamide is an anionic polyacrylamide which helps to absorb more water. It can be shown in Figure 1.

In this research, SPHs indicate optimum condition at $0.4 \mathrm{wt} \%$ of sodium bicarbonate with 99.10 $\pm 3.35 \mathrm{~g} / \mathrm{g}$ of water absorbency. However, water absorbency decreases at $79.66 \pm 4.89$ to $46.64 \pm 4.51$ $(\mathrm{g} / \mathrm{g})$ with the increased amount of $\mathrm{NaHCO}_{3}$ from
0.6 wt $\%$ to 1.0 wt $\%$. Table 1 shows that the higher concentration of sodium bicarbonate, the lower the water absorbency of superporous hydrogels. The reason is because the concentration of $\mathrm{NaHCO}_{3}$ was too high, so the network holes formed were bigger. In addition, the absorption ability of water molecules was weaker due to larger network space that slower the swelling properties of hydrogels. Other than that, the higher amount of foaming agent, the more amount of excess was left which slow down the water absorption. All the results were obtained at equilibrium time for $24 \mathrm{~h}$.

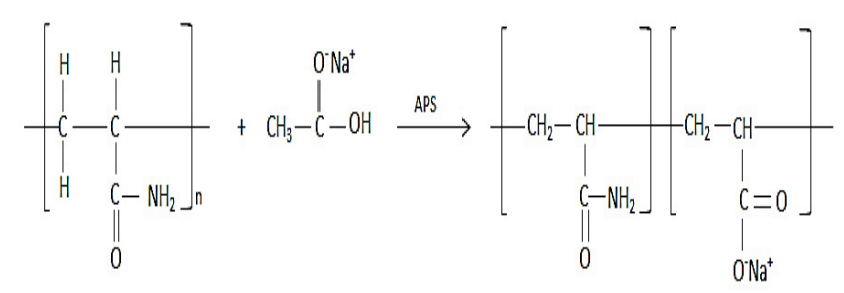

Figure 1. Reaction mechanism acrylamide monomer in superporous hydrogels.

Table 1. Water absorbency of superporous hydrogels

\begin{tabular}{|l|l|}
\hline $\begin{array}{l}\text { Concentration of Sodium } \\
\text { Bicarbonate (wt \%) }\end{array}$ & $\begin{array}{l}\text { Water Absorbency } \pm \text { Error } \\
(\mathrm{g} / \mathrm{g})\end{array}$ \\
\hline 0.0 & $59.90 \pm 3.96$ \\
\hline 0.2 & $76.94 \pm 2.33$ \\
\hline 0.4 & $99.10 \pm 3.35$ \\
\hline 0.6 & $79.66 \pm 4.89$ \\
\hline 0.8 & $56.05 \pm 2.55$ \\
\hline 1.0 & $46.64 \pm 4.51$ \\
\hline
\end{tabular}

\subsection{Swelling Kinetics Study}

The swelling mechanism of hydrogels is described by second order kinetics that has been proposed by Aydınoğlu ${ }^{7}$. It was shown clearly from the Figure 2 that all the swelling values showed the well correlation with Equation 3.

According to Equation (3), the swelling data must fit with slope of $\frac{1}{W_{\infty}}$ and an ordinate of intercept $\frac{1}{K W_{\infty}^{2}}$. Based on the Figure 2, it was found that the swelling data for all SPHs gives a straight line. Therefore, the swelling behaviours of SPHs obey the second order kinetics.

Table 2 shows that the swelling rate constant $\mathrm{K}$ with the foaming agent content. According to the data in Table 
2, it means that the swelling process proceeded faster at low amounts of foaming agent due to the high porosity of hydrogels as shown in Figure 3 (b). Other than that, the lower in $\mathrm{K}$ values produces higher interaction between polymer-solvents. However, in this research $0.4 \mathrm{wt} \%$ $\mathrm{NaHCO}_{3}$ produced optimum K values which gives SPHs produced higher water absorbency at faster rate of swelling.

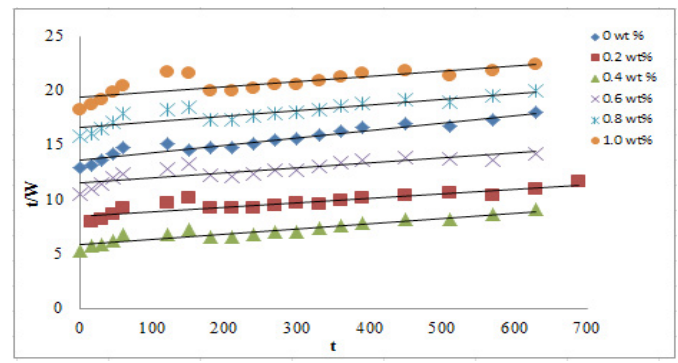

Figure 2. Second Order Plot of (t/W) against Time (min).

Table 2. Effect of chemical composition on the swelling kinetics of hydrogels

\begin{tabular}{|l|l|}
\hline $\begin{array}{l}\text { Concentration } \mathrm{NaHCO}_{3} \\
(\mathrm{wt} \%)\end{array}$ & $\mathrm{K}$ \\
\hline 0.0 & $1.29443 \mathrm{E}-05$ \\
\hline 0.2 & $1.50837 \mathrm{E}-05$ \\
\hline 0.4 & $1.1905 \mathrm{E}-05$ \\
\hline 0.6 & $1.30809 \mathrm{E}-05$ \\
\hline 0.8 & $1.61002 \mathrm{E}-05$ \\
\hline 1.0 & $1.78762 \mathrm{E}-05$ \\
\hline
\end{tabular}

\subsection{Surface Morphology of Hydrogel}

Figure 3 shows the SEM image of SPHs. Based on Figure 3 (a) and (c), it shows smooth surface and less pore were produces while (b) possessed large number of pores. Figure 3(b) expressing that formation of hydrogel with the superporous structure would not destroy the structure of hydrogels. Moreover, the uneven and coarse surface of hydrogels was beneficial to the swelling properties. In addition, inner surface of SPHs contain large number of pores that was connected to each other. Then, pore that form connections or channels with interior structure will resulted great penetration of the medium into the structure of hydrogels. The connected pore help the hydrogels swell near to equilibrium size in short period of time. According to the data in Table 2, $0.4 \mathrm{wt} \% \mathrm{NaHCO}_{3}$ has lower $\mathrm{K}$ value, thus gives the significant result with the morphology of SPHs itself as it contain more porous structure compared between $0 \mathrm{wt} \%$ and $1.0 \mathrm{wt} \%$. Besides, the capillary channels caused water able to enter into hydrogels networks make it diffuse through the structure of hydrogels. Therefore, it was rapidly increase the absorption performance of hydrogels.
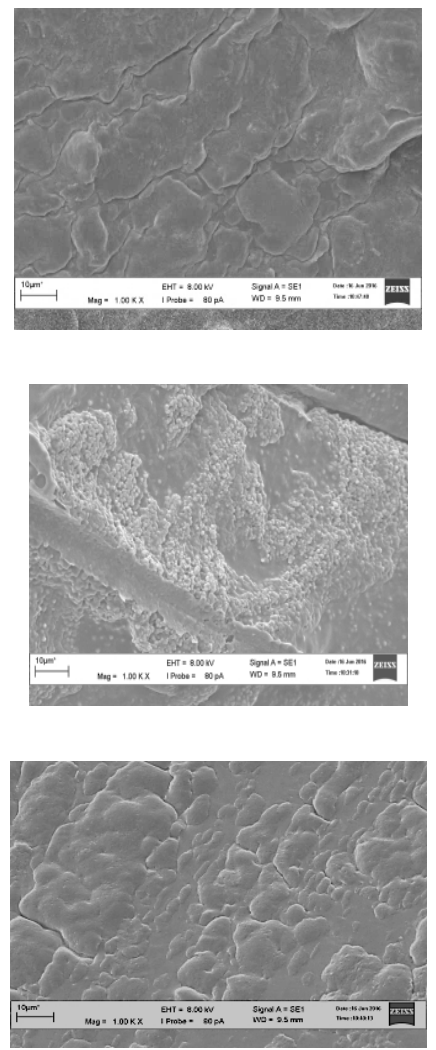

Figure 3. SEM image showing superporous hydrogel at $1.0 \mathrm{~K}$ magnification with different amount of foaming concentration; (a) 0 wt $\% \mathrm{NaHCO}_{3}$, (b) $0.4 \mathrm{wt} \% \mathrm{NaHCO}_{3}$ (c) $1.0 \mathrm{wt} \% \mathrm{NaHCO}_{3}$.

\subsection{Fourier Transform Infrared(FTIR) Spectroscopy}

FTIR analysis is an effective technique to study the structure of the polymer. Figure 4 shows the FTIR spectra of pure hydrogels and $0.4 \mathrm{wt} \% \mathrm{NaHCO}_{3}$ superporous hydrogels (SPHs). Based on Figure 4, both spectra show almost the same functional groups. It indicates that, both contain same structure of SPHs. Both FTIR shows a broad absorption band at $3500-3100 \mathrm{~cm}^{-1}$ due to the $\mathrm{N}-\mathrm{H}$ stretching of amide groups of acrylamide units. For pure hydrogels, the peaks at around $1643.56 \mathrm{~cm}^{-1}$ and 1543.28 $\mathrm{cm}^{-1}$ arise from amide-I and amide II cause by the presence of acrylamide units. Then, $\mathrm{C}-\mathrm{N}$ and $\mathrm{C}-\mathrm{H}$ stretching bands appear at 1421.30 and $2916.85 \mathrm{~cm}^{-1}$, respectively, 
thus confirming the presence of amide groups ${ }^{8}$. In addition, absorption at $1643.56 \mathrm{~cm}^{-1}$ also assigned for water molecule which tightly binds at the hydrogel molecules. Other than that, at peak around 1595.83 and 1421.30 $\mathrm{cm}^{-1}$ there are assigned the $\mathrm{C}=\mathrm{O}$ stretching vibration of the ionic carboxyl group (-COO-). At $1393.82 \mathrm{~cm}^{-1}$, the absorption band belongs to $\mathrm{CH}_{2}$ which is supported by the absorbance at $2916.85 \mathrm{~cm}^{-1}$. Lastly, in the FTIR spectrum of $0.4 \mathrm{wt} \% \mathrm{NaHCO}_{3} \mathrm{SPHs}$ refers the main peak as follows; $2903.84 \mathrm{~cm}^{-1}\left(\mathrm{CH}_{2}\right.$ stretching), $1680.20 \mathrm{~cm}^{-1}$ (amide I bond), and $1527.37 \mathrm{~cm}^{-1}$ (amide II bond). As a conclusion, similar peaks were confirmed the presence of same unit groups in the hydrogel.

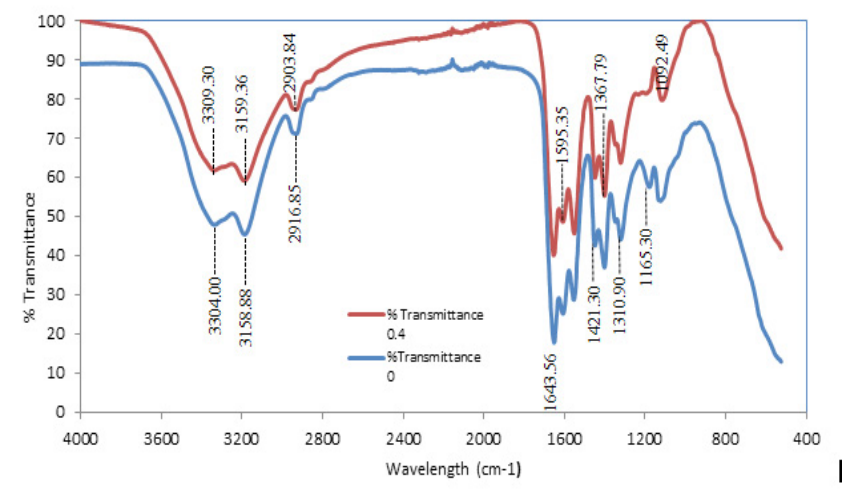

Figure 4. FTIR spectra for (a) Pure hydrogels, (b) $0.4 w t \%$ $\mathrm{NaHCO}_{3} / \mathrm{PAM}$.

\section{Conclusion}

Novel PAM hydrogels containing foaming agent were synthesized to improve the swelling properties of hydrogel. It was found that sodium bicarbonate provided good swelling to the hydrogels. It was concluded that, the addition of $0.2 \mathrm{wt} \% \mathrm{NaHCO} 3$ gives approximately $28 \%$ increased of water absorbency. The hydrogels prepared with foaming agent swell much more than those without it. It shows that the interaction between monomer and various functional groups of sodium bicarbonate play an important role on swelling ratios. In addition, kinetics was calculated for all types of hydrogels. It shows that less foaming agent results low swelling constant. The result shows performance was optimum at $0.4 \mathrm{wt} \% \mathrm{NaHCO} 3$. Lastly, SPHs can be used in agriculture sector or any other sectors as it was $65 \%$ better from the absorbent polymer. The International Conference on Fluids and Chemical Engineering (FluidsChE 2017) is the second in series with complete information on the official website ${ }^{9}$ and organ- ised by The Center of Excellence for Advanced Research in Fluid Flow (CARIFF) ${ }^{10}$. The publications on products from natural resources, polymer technology, and pharmaceutical technology have been published as a special note in volume $2^{11}$. The conference host being University Malaysia Pahang ${ }^{12}$ is the parent governing body.

\section{References}

1. Sutradhar SC, Mizanur M, Khan R. The Synthesis of Superabsorbent Polymers from a Carboxymethylcellulose / Acrylic Acid Blend Using Gamma Radiation and its Application in Agriculture. Journal of Physical Science. 2015; 26(2):23-39.

2. Mastropietro DJ, Omidian H, Park K. Drug delivery applications for superporous hydrogels. Expert Opinion on Drug Delivery. 2012; 9(1):71-89. https://doi.org/10.1517/1 7425247.2012.641950 PMid:22145909

3. Kumar A, Pandey M, Koshy MK, Saraf SA. Synthesis of fast swelling superporous hydrogel: effect of concentration of crosslinker and acdisol on swelling ratio and mechanical strength. International Journal of Drug Delivery. 2010; 2(2):135-40. https://doi.org/10.5138/ ijdd.2010.0975.0215.02022

4. Mahdavinia GR, Mousavi SB, Karimi F, Marandi GB, Garabaghi H, Shahabvand S. Synthesis of porous poly(acrylamide) hydrogels using alcium carbonate and its application for slow release of potassium nitrate. Express Polymer Letters. 2009; 3(5):279-85. https://doi. org/10.3144/expresspolymlett.2009.35

5. El-Haggar SM, Elkersh H. Sustainability and Innovation: The Next Global Industrial Revolution. New York: American University in Cairo Press. 2016. https://doi.org/10.5743/ cairo/9789774166471.001.0001 PMid:26902691

6. Najib NN, Ariff ZM, Manan NA, Bakar AA, Sipaut CS. Effect of Blowing Agent Concentration on Cell Morphology and Impact Properties of Natural Rubber Foam. Journal of Physical Science. 2009; 20(1):13-25.

7. Aydinoglu D. Investigation of $\mathrm{pH}$-dependent swelling behavior and kinetic parameters of novel poly (acrylamideco-acrylic acid) hydrogels with spirulina. E-Polymers. 2015; 15(2):81-93. https://doi.org/10.1515/epoly-2014-0170

8. Li D, Zhang X, Yao J, Simon GP, Wang H. Stimuli-responsive polymer hydrogels as a new class of draw agent for forward osmosis desalination. Chemical Communications. 2011; 47(6):1710-2. https://doi.org/10.1039/c0cc04701e PMid:21203629

9. FluidChe 2017 Available from: http://fluidsche.ump.edu. my/index.php/en/

10. The Center of Excellence for Advanced Research in Fluid Flow (CARIFF) Available from: http://cariff.ump.edu.my/ 
11. Natural resources products prospects - International Conference on Fluids and Chemical Engineering FluidsChE 2017 Malaysia, ). Indian Journal of science and technology. 2017; S2(1).
12. University Malaysia Pahang. Available from: www.ump. edu.my 